\title{
Antioxidant Activities of Dendrophthoe falcata (L.f. ) Etting
}

\author{
Nipun Dashora, Vijay Sodde, Kirti. S. Prabhu and Richard Lobo* \\ Department of Pharmacognosy, Manipal College of Pharmaceutical Sciences, Manipal University, Manipal, Karnataka, \\ India
}

\begin{abstract}
Dendrophthoe falcata is a parasitic plant used in traditional medicine as an aphrodisiac, astringent, and diuretic and for pulmonary tuberculosis, asthma, menstrual disorder, swelling, and wound. The present study primarily describes the antioxidant activities of methanolic and aqueous extracts of the stem of $D$. falcate in different in vitro models. Both methanolic and aqueous extracts exhibited antioxidant activity, with $\mathrm{IC}_{50}$ values at 18 and $26 \mu \mathrm{g} / \mathrm{mL}$ for DPPH, 22 and 29 $\mu \mathrm{g} / \mathrm{mL}$ for ABTS, 62 and $75 \mu \mathrm{g} / \mathrm{mL}$ for NO scavenging activities, 260 and $180 \mu \mathrm{g} / \mathrm{mL}$ for total antioxidant capacity, respectively. Total phenolic content for methanolic and aqueous extracts were found to be 1.5 and $1.1 \mathrm{mg} / \mathrm{g}$ while total flavonoid content were found to be 0.140 and $0.029 \mathrm{mg} / \mathrm{g}$. The overall antioxidant activity might be attributed to its polyphenolic, flavonoid and phytosterol constituents.
\end{abstract}

Keywords: Dendrophthoe falcate, antioxidant activity, flavonoids, phenolics, DPPH, ABTS, NO scavenging activity.

\section{INTRODUCTION}

Dendrophthoe falcata (L.f.) Ettingsh. (mistletoe), also known as Loranthus longiflorus Desr., is a perennial climbing woody parasitic plant. It is indigenous to tropical regions especially in India, Srilanka, Thailand, China, Australia, Bangladesh, Malayasia and Myanmar. In India it is widely distributed throughout upto $900 \mathrm{~m}$ [1]. Preliminary phytochemical screening conducted in our department revealed the presence of carbohydrates, phytosterols, flavonoids, glycosides and phenolic compounds [2].

Warrier (1993) reported that the entire plant is used extensively in traditional system of medicine as an aphrodisiac, astringent, narcotic, diuretic, and for the treatment of pulmonary tuberculosis, asthma, menstrual disorders, swellings, wounds, and ulcers [3]. In view of its wide use and its chemical composition, the methanolic and aqueous extracts of $D$. falcata stem were determined for their in vitro anti oxidative activities.

\section{MATERIAL AND METHODS}

\section{Chemical and Reagents}

1,1-Diphenyl-2-picryl hydrazine (DPPH), 2, 2-azino bis (3-ethyl benzo thiazoline-6-sulphonic acid (ABTS), and quercetin were purchased from Sigma Chemicals, USA. Gallic acid was obtained from Nice Chemicals, Mumbai. Ascorbic acid (Ranbaxy Fine Chemicals Ltd.) was used as standard for the study.

\section{Plant Material and Preparation of the Extracts}

The stem of D. falcata was collected in August 2009 from Manipal. The plant was identified by Dr.

\footnotetext{
*Address Correspondent to this author at Department of Pharmacognosy, Manipal College of Pharmaceutical Sciences, Manipal University, Manipal, Karnataka, India; Tel: 0820-22482; Fax: 0820-2571998;

E-mail: avemaria_lobo@yahoo.com
}

Gopalakrishna Bhat, Taxonomist, Poorna Prajna College, Udupi, Karnataka. A voucher specimen (PP 564) is deposited in the Department of Pharmacognosy, Manipal College of Pharmaceutical Sciences (Manipal, India).

$100 \mathrm{~g}$ powder of shade dried stems were extracted with methanol by hot extraction process (soxhlet) for $72 \mathrm{~h}$. After completion of the extraction the solvent was recovered by distillation and concentrated in vacuo. The aqueous extract was prepared by maceration process with $100 \mathrm{~g}$ of the stem powder using chloroform:water (1:99) for seven days, after completion of the extraction the solvent was recovered by distillation and concentrated in vacuo.

\section{Antioxidant Activity Assays}

\section{1-Diphenyl-2-Picryl Hydrazine (DPPH) Radical Scavenging Activity}

The antiradical activity for the plant extracts was assessed on the basis of the radical-scavenging effect of the stable DPPH free radical. The concentration of DPPH was kept at $300 \mu \mathrm{M}$ in $\mathrm{MeOH} .1 \mathrm{mg}$ of the extracts dissolved separately in $1 \mathrm{~mL}$ of $\mathrm{MeOH}$, from which different concentrations $(5-200 \mu \mathrm{g} / \mathrm{mL})$ were prepared. $10 \mu \mathrm{L}$ of each extract solution was allowed to react with $200 \mu \mathrm{L} \mathrm{DPPH}$ at $37^{\circ} \mathrm{C}$ for $30 \mathrm{~min}$ in a 96-well microliter plate. After incubation, decrease in absorption for each solution was measured at 490 $\mathrm{nm}$ using a microplate reader. Ascorbic acid was used as reference [4].

\section{2-Azino Bis (3-Ethyl Benzo Thiazoline-6-Sulphonic Acid (ABTS) Radical Scavenging Activity}

For ABTS assay, the stock solutions of $7.4 \mathrm{mM}$ ABTS and $2.6 \mathrm{mM}$ potassium persulfate were prepared and the working solution was then prepared by mixing the two stock solutions in equal quantities and allowing them to react for $16 \mathrm{~h}$ at room temperature in a dark place. The solution was then diluted by mixing $\mathrm{ABTS}^{-+}$solution with methanol to 
obtain an absorbance of $1.00 \pm 0.02$ units at $734 \mathrm{~nm}$ using the spectrophotometer. Fresh $\mathrm{ABTS}^{-+}$solution was prepared for each assay. Different concentrations of standard solution of ascorbic acid were prepared. The $1 \mathrm{mg}$ of the extracts dissolved separately in $1 \mathrm{~mL}$ of $\mathrm{MeOH}$, from which different concentrations $(5-200 \mu \mathrm{g} / \mathrm{mL})$ were prepared. $200 \mu \mathrm{L}$ of each concentration was allowed to react with $4 \mu \mathrm{L}$ of the ABTS ${ }^{-+}$ for $2 \mathrm{~h}$ in a dark place. Then, the absorbance was read at 734 $\mathrm{nm}$ [5].

\section{Nitric Oxide (NO) Scavenging Activity}

Sodium nitroprusside in aqueous solution at physiological $\mathrm{pH}$ spontaneously generates nitric oxide (NO), which interacts with oxygen to produce nitrite ions. The nitrite ions can be determined by Griess Illosvoy reaction [6]. $2 \mathrm{~mL}$ of $10 \mathrm{mM}$ sodium nitroprusside in $0.5 \mathrm{~mL}$ phosphate buffer saline ( $\mathrm{pH} 7.4$ ) was mixed with $0.5 \mathrm{~mL}$ of extract at various concentrations and the mixture incubated at $25^{\circ} \mathrm{C}$ for 150 min. From the incubated mixture $0.5 \mathrm{~mL}$ was taken out and added into $1.0 \mathrm{~mL}$ sulfanilic acid reagent (33\% in $20 \%$ glacial acetic acid) and incubated at room temperature for 5 min. Finally $1.0 \mathrm{~mL}$ naphthylethylenediamine dihydrochloride $(0.1 \% \mathrm{w} / \mathrm{v})$ was mixed and incubated at room temperature for $30 \mathrm{~min}$. The absorbance at $540 \mathrm{~nm}$ was measured with a spectrophotometer. The nitric oxide radical scavenging activity was calculated according to the following equation:

$$
\% \text { Inhibition }=\left[\left(\mathrm{A}_{0}-\mathrm{A}_{1}\right) / \mathrm{A}_{0} \times 100\right]
$$

Where $A_{0}$ was the absorbance of the control (blank, without extract) and $A_{1}$ was the absorbance in the presence of the extract/Standard [7].

\section{Total Antioxidant Capacity}

Total antioxidant capacity was measured according to the method reported by Prieto et al. [8]. In brief, $100 \mu \mathrm{g}$ of extract and $100 \mu \mathrm{g}$ of ascorbic acid (as standard) were taken in $0.1 \mathrm{~mL}$ of alcohol, combined separately in an eppendroff tube with $1.9 \mathrm{~mL}$ of reagent solution $(0.6 \mathrm{M}$ sulphuric acid, $28 \mathrm{mM}$ sodium phosphate, and $4 \mathrm{mM}$ ammonium molybdate). The tubes were capped and incubated in a thermal block at $95^{\circ} \mathrm{C}$ for $90 \mathrm{~min}$. After the samples were cooled to room temperature, the absorbance of the aqueous solution of each was measured at $695 \mathrm{~nm}$ against a blank. A typical blank solution contained $1.9 \mathrm{~mL}$ of reagent solution and the appropriate volume of the same solvent used for the sample and it was incubated under the same conditions as the rest of the samples. For samples of unknown composition, watersoluble antioxidant capacities are expressed as equivalents of ascorbic acid. Ascorbic acid equivalents were calculated using standard graph of ascorbic acid. The experiment was conducted in triplicate and values are expressed as ascorbic acid equivalents in $\mu \mathrm{g} / \mathrm{mL}$ of extract.

\section{Total Phenolics}

Total soluble phenolics in the extracts were determined with Folin-Ciocalteu reagent using gallic acid as a standard phenolic compound. $1.0 \mathrm{~mL}$ of extract solution containing $1.0 \mathrm{mg}$ extract was diluted with $46 \mathrm{~mL}$ of distilled water in a volumetric flask. $1.0 \mathrm{~mL}$ of Folin-Ciocalteu reagent was added and the content of the flask mixed thoroughly. $3 \mathrm{~min}$ later $3.0 \mathrm{~mL}$ of $2 \%$ sodium carbonate was added and the mixture was allowed to stand for $2 \mathrm{~h}$ with intermittent shaking. The absorbance of the blue color that developed was read at $760 \mathrm{~nm}$. The concentration of total phenols was expressed as gallic acid equivalents in $\mathrm{mg} / \mathrm{g}$ of dry extract [9].

\section{Total Flavonoids}

Aluminum chloride colourimetric method was used for determination of flavonoids. To the $10 \mathrm{~mL}$ volumetric flask $2 \mathrm{~mL}$ of water and $1 \mathrm{~mL}$ of plant extract $(1 \mathrm{mg} / \mathrm{mL})$ were added. After $5 \mathrm{~min} 3 \mathrm{~mL}$ of $5 \%$ sodium nitrite and $0.3 \mathrm{~mL}$ of $10 \%$ aluminum chloride were added. After $6 \mathrm{~min}, 2 \mathrm{~mL}$ of $1 \mathrm{M}$ sodium hydroxide was added and the volume made up to $10 \mathrm{~mL}$ with water. Absorbance was measured at 510 $\mathrm{nm}$. The percentage of total flavonoids were calculated from calibration curve of quercetin $(10-250 \mu \mathrm{g})$ plotted by using the same procedure and total flavonoids was expressed as quercetin equivalents in milligrams per gram sample [10].

\section{RESULTS AND DISCUSSION}

Methanolic and aqueous extracts of D. falcata exhibited antioxidant activity in different in vitro models (Table 1). $\mathrm{IC}_{50}$ values of methanolic and aqueous extracts were 260 $\mu \mathrm{g} / \mathrm{mL}$ and $180 \mu \mathrm{g} / \mathrm{mL}$ for total antioxidant capacity, 18 $\mu \mathrm{g} / \mathrm{mL}$ and $26 \mu \mathrm{g} / \mathrm{mL}$ for DPPH (Fig. 1) and $22 \mu \mathrm{g} / \mathrm{mL}$ and $29 \mu \mathrm{g} / \mathrm{mL}$ for ABTS (Fig. 2), $62 \mu \mathrm{g} / \mathrm{mL}$ and $75 \mu \mathrm{g} / \mathrm{mL}$ for nitric oxide radicals with $\mathrm{IC}_{50}$ values $62 \mu \mathrm{g} / \mathrm{mL}$ and 75 $\mu \mathrm{g} / \mathrm{mL}$ for NO scavenging activity (Fig. 3), respectively. Total phenolic content for methanolic and aqueous extracts were found to be $1.5 \mathrm{mg} / \mathrm{g}$ and $1.1 \mathrm{mg} / \mathrm{g}$ respectively (equivalent to gallic acid). The total flavonoid content for methanolic and aqueous extracts were found to be 0.140 $\mathrm{mg} / \mathrm{g}$ and $0.029 \mathrm{mg} / \mathrm{g}$ respectively (equivalent to quercetin).

Phenolics present in fruits and vegetables have received considerable attention because of their potential antioxidant activities [11]. Phenolic compounds undergo a complex redox reaction with phosphotungstic and phosphomolybdic acids present in the Folin-Ciocalteu reagent [12]. However, it should be noted that some chemical group of amino acids,

Table 1. In Vitro Antioxidant Activities of Dendrophthoe falcata Stem Extracts

\begin{tabular}{|l|c|c|c|c|}
\hline \multirow{2}{*}{ Sample } & \multicolumn{3}{|c|}{ Antioxidant Activity $\left(I_{\mathbf{5 0}}, \mu \mathrm{g} / \mathrm{mL}\right)$} \\
\cline { 2 - 5 } & DPPH & ABTS & Nitric Oxide Scavenging Activity & Total Antioxidant Capacity \\
\hline \hline Methanolic Extract & 18 & 22 & 62 & 260 \\
\hline Aqueous Extract & 26 & 29 & 75 & 180 \\
\hline Ascorbic Acid & 8.2 & 12 & 26 & - \\
\hline
\end{tabular}




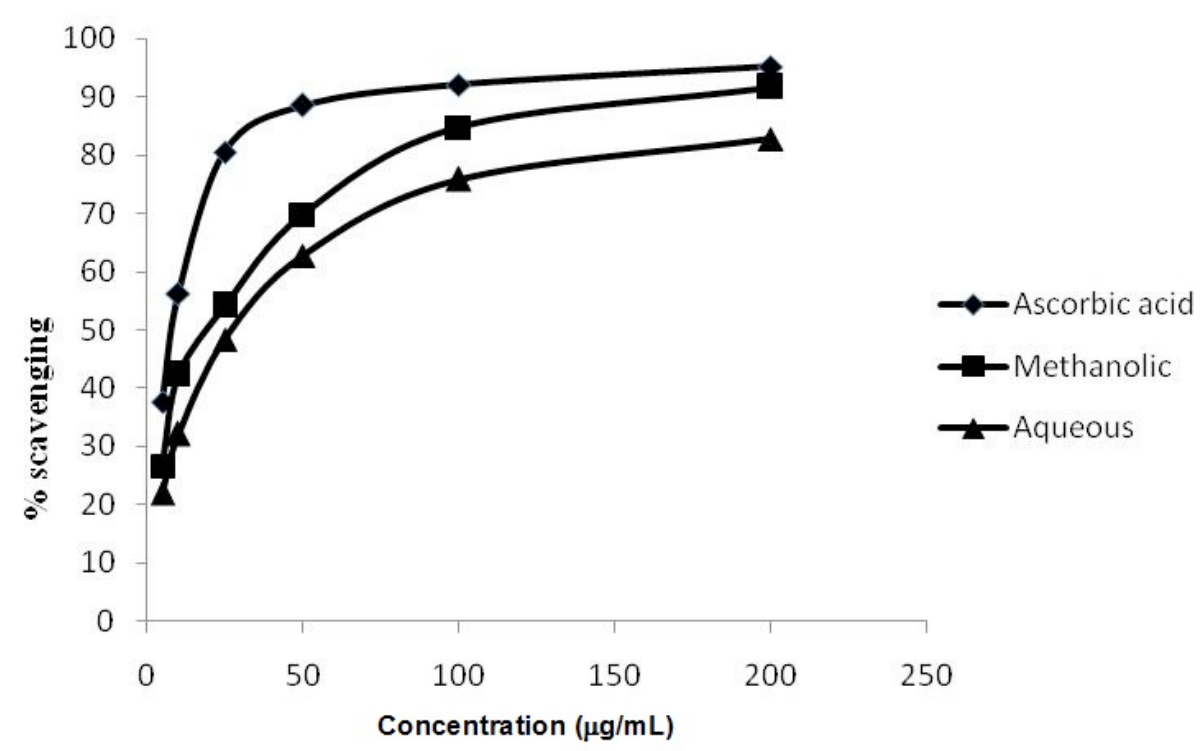

Fig. (1). DPPH scavenging activity of Dendrophthoe falcata stem extracts.

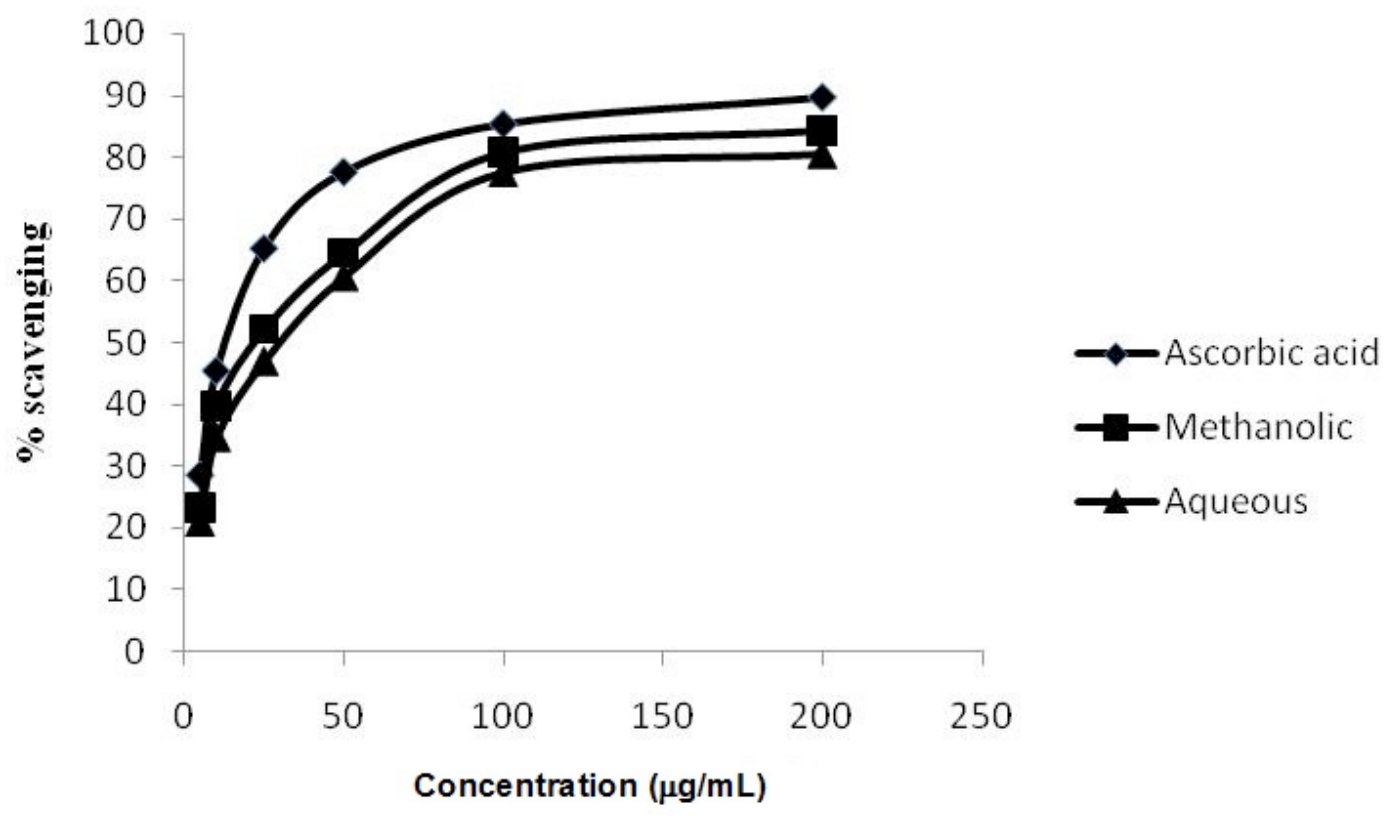

Fig. (2). ABTS scavenging activity of Dendrophthoe falcata stem extracts.

proteins, organic acids, sugars and aromatic amines could react with the reagent. In this investigation, D. falcata stem was dried before extraction while ascorbic acid was lost during drying process and amino acids, proteins and sugars could be removed from the extraction solvents. Thus, interference from ascorbic acid or other compounds like amino acids, proteins and sugars should be very little [13].

Hydrogen donation is the main mechanism of phenolics as antioxidants. The lower strength of the $\mathrm{O}-\mathrm{H}$ bond present in phenolics corresponds to a higher scavenging activity. Quercetin identified from D. falcata [14] has C2-C3 double bond and a C-3 hydroxyl group while the most active hydroxyl groups for hydrogen donation are those attached to
C4 and C3 positions [13]. Thus, the antioxidant activity of flavonoids could be related to the hydroxyl group.

The results obtained in the present study indicate that $D$. falcata stem extracts exhibit potent free radical scavenging and antioxidant activity. The overall antioxidant activity might be attributed to its polyphenolic content and other phytochemical constituents. The findings of the present study suggest that $D$. falcata stem could be a potential source of natural antioxidant that could have great importance as therapeutic agents in preventing or slowing the progress of aging and age associated oxidative stress related degenerative diseases. The presence of phytoconstituents like quercetin can be attributed to the antioxidant property of the plant. 


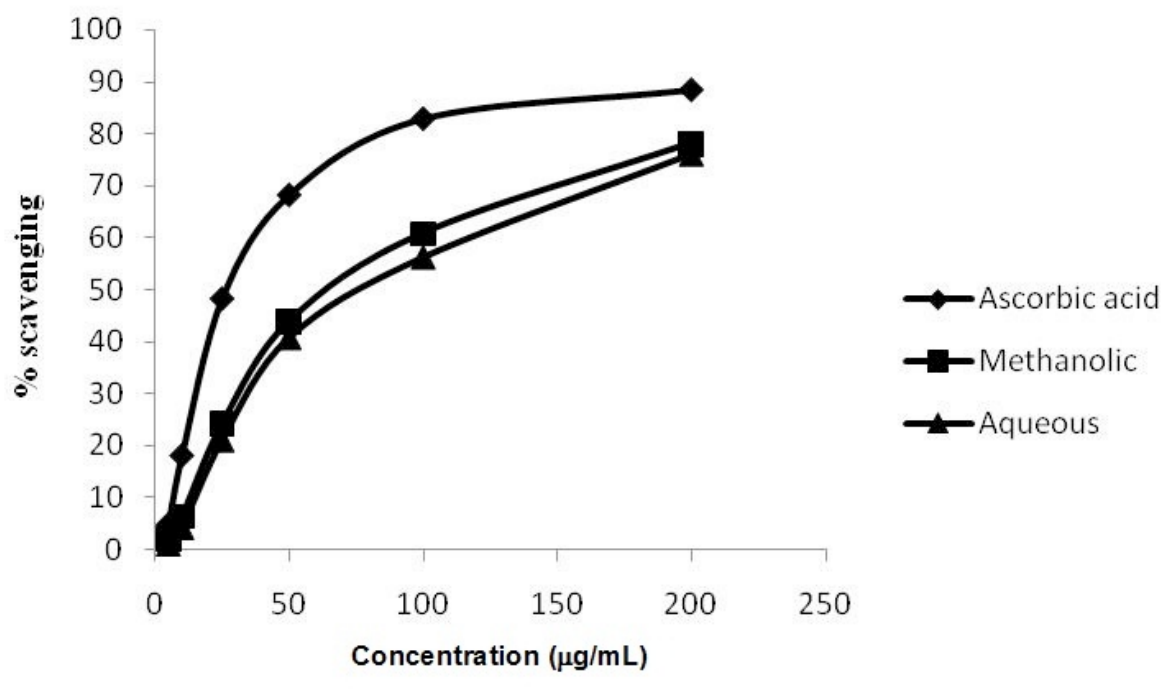

Fig. (3). Nitric oxide scavenging activity of Dendrophthoe falcata stem extracts.

\section{ACKNOWLEDGEMENT}

The authors sincerely thank Manipal College of Pharmaceutical Sciences, Manipal University, Manipal, India for providing all facilities to carry out this study.

\section{ABBREVIATIONS}

$\begin{array}{ll}\text { ABTS }= & 2,2-\text { Azino bis }(3-\text {-ethyl Benzo Thiazoline } \\ & -6-\text { Sulphonic acid } \\ \text { DPPH } & 1,1-\text { Diphenyl-2- Picryl Hydrazine } \\ \text { IC }_{50} & \text { Half maximal Inhibitory concentration } \\ \text { NO } & =\text { Nitric oxide } \\ \text { ROS } & =\end{array}$

\section{REFERENCES}

[1] Pattanayak, S.P.; Mazumder, P.M.; Priyashree, S. Dendrophthoe falcata (L.f) Ettingsh: A consensus review. Phcog. Rev., 2008, 2, 359-68.

[2] Dashora, N.; Agrawal, R.; Sodde, V.; Prabhu, K.S.; Lobo, R. Pharmacognostical evaluation of Dendrophthoe falcata. J. pharm. Res., 2010, 3(5), 971-4.

[3] Warrier, P K.; Nambiar, V.P.K.; Ramankutty, C. Indian Medicinal Plants a Compendium of 500 Species. $2^{\text {nd }}$ ed.; Orient Longman: India, 1993.

[4] Peihong, F.; Terrier, L.; Hay, A.E.; Marston, A.; Hostettmann, K. Antioxidant and enzyme inhibition activities and chemical profiles of Polygonum sachalinensis F.Schmidt ex Maxim (Polygonaceae). Fitoterapia, 2010, 81, 124-31.
[5] Rajaei, A.; Barzegar, A.; Mobarez, A.M.; Sahari, M.A.; Esfahani, Z. H. Antioxidant, anti-microbial and antimutagenicity activities of pistachio (Pistachia vera) green hull extract. Food Chem. Toxicol., 2010, 48, 107-12.

[6] Nagda, D.; Saluja, A.; Nagda, C. Antioxidant activities of methanolic and aqueous extracts from leaves of Martynia annua Linn. Phcog. J., 2009, 1, 288-97.

[7] Nair, S.; Rao, M.N.A.; Priyadarsini, K.I.; Devasagayam, T.P.A. Inhibition of radiation induced peroxidation by Curcumin. Int. J. Pharm., 1997, 151, 127-30.

[8] Prieto, P.; Pineda, M.; Aguilar, M. Spectrophotometric quantitation of antioxidant capacity through the formation of a phosphomolybdenum complex: specific application to the determination of vitamin E1. Anal. Biochem., 1999, 269, 337-41.

[9] Singleton, V.L.; Rossi, J.A. Colorimetry of total phenolics with phosphotungtic acid reagents. Am. J. Enol. Viticult., 1965, 16, 14458.

[10] Chang, C.; Yang, M.H.; Wen, H.M.; Chen, J.C. Estimation of total flavonoids content in propolis by two complementary colorimetric methods. J. Food Drug Anal., 2002, 10, 178-82.

[11] Pan,Y.; Wang, K.; Huang, S.; Wang, H.; Mu, X.; He, C. Antioxidant activity of microwave-assisted extract of longan (Dimocarpus longan Lour.) peel. Food Chem., 2008, 106, 1264-70.

[12] Amin, A.; Yazdanparast, R. Antioxidant and free radical scavenging potential of Achillea santolina extracts. Food Chem., 2007, 104, 21-9.

[13] Prasad, N.K.; Yang, B.; Dong, X.; Jiang, G.; Zhang, H.; Xie,H.; Jiang, Y. Flavonoid contents and antioxidant activities from Cinnamomum species. Innovative Food Sci. Emerg. Technol., 2009, 10, 627-32.

[14] Dashora, N.; Sodde, V.; Bhagat, J.; Prabhu, K.S.; Lobo, R. Antitumor activity of Dendrophthoe falcata against Ehrlich Ascites Carcinoma in Swiss Albino mice. Pharm. Crops., 2011, 2, 1-7. 